\title{
Orexin A Controls Glucose Metabolism
}

\author{
Messina $\mathbf{G}^{1}$, Dalia $\mathbf{C}^{1}$, Tafuri $D^{3}$, Palmieri $F^{1}$, Dato $A^{1}$, Russo $A^{1}$, De Blasio $\mathbf{S}^{1}$, Messina $\mathbf{A}^{1}$, De Luca $\mathbf{A}^{2}$, Chieffi $\mathbf{S}^{1}$ and Monda $\mathbf{M}^{1^{*}}$ \\ ${ }^{1}$ Department of Experimental Medicine, Section of Human Physiology, and Clinical Dietetic Service, Second University of Naples, Via Costantinopoli 16, 80138 Naples, \\ Italy
}

${ }^{2}$ Department of Psychiatry, University of Toronto, Toronto, Ontario, Canada

${ }^{3}$ Faculty of Motor Sciences, University of Naples "Parthenope", Naples, Italy

*Corresponding author: Marcellino Monda, MD, Department of Experimental Medicine, Section of Human Physiology, and Clinical Dietetic Service, Second University of Naples, Via Costantinopoli 16, 80138 Naples, Italy, Tel: +39 +81 566 5804; Fax +39 +81 5667500; E-mail: marcellino.monda@unina2.it

Received: May 14, 2014, Accepted: June 23, 2014, Published: June 30, 2014

Copyright: ( 2014 Monda M, et al. This is an open-access article distributed under the terms of the Creative Commons Attribution License, which permits unrestricted use, distribution, and reproduction in any medium, provided the original author and source are credited.

\begin{abstract}
The orexin-A and orexin-B are a hypothalamic neuropeptides, involved in the regulation of feeding behaviour, sleep-wakefulness rhythm, and neuroendocrine homeostasis that influence the sympathetic nervous system activity, blood pressure regulation, and metabolic status, glycemic, and may contribute to increase diabetics morbidity and mortality. This review concentrates on the catabolic role of orexin, which paradoxically coexists with its anabolic feeding-inducing role. This review aims to provide insight into the biological mechanism that controls orexin's role in energy expenditure and to discuss its significance in the context of glycemic control.

On the other hands, hypothalamus regulates muscle glucose metabolism and its insulin sensitivity; in fact the ventromedial hypothalamus increases glucose uptake in certain peripheral tissues, including brown adipose tissue.

The circumstance that it has been found a relationship between brown adipose tissue, orexins, glucose, insulin levels suggests new research focused on the possible roles of orexins in many anomalies of energy expenditure and of glucose homeostasis, with reference to the diabetic patient.
\end{abstract}

Keywords: Obesity; Orexin; Fat; Energy expenditure; Glucose homeostasis

\section{Epidemiological Data}

Obesity and diabetes are a worldwide public health issue with extensive medical, social, and economic consequences [1,2]. Obesity, which is defined by the presence of excess adiposity, has negative effects on health and it increases the risk of developing a variety of medical conditions, including cardiovascular disease, some cancers, and diabetes mellitus [3-6]. Over the past three decades, the prevalence of obesity has doubled in the USA and in Europe country $[7,8]$. At the moment, an astounding two-thirds of the US population is overweight and about one-third, or roughly 100 million Americans, are obese $[8,9]$. Although according to the most recent data published in the 2005-2006 update of the National Health and Nutrition Examination Survey (NHANES) obesity rates have stabilized, others expect that the obesity 'epidemic' will only continue to worsen, with as many as $75 \%$ of Americans and Europeans potentially being overweight in the year 2020 [10]. Physicians will undoubtedly encounter obese persons in clinical practice and they must, therefore, be able to identify and address specific needs to this population of patients.

\section{Energy Homeostasis}

It is extremely important for the health and disease to understand appetite regulation and energy expenditure mechanisms. The awareness that the distributions of these regulatory mechanisms play a central role in the pathogenesis of obesity and associated metabolic syndrome is not new, and it is even more interesting to understand what happens in a diabetic patient.

Resting Energy Expenditure (REE) accounts for $60-75 \%$ of total daily energy expenditure. Several factors contribute to the inter individual variability in REE such as Free Fat Mass (FFM) [11], Sympathetic Nervous System (SNS) activity $[12,13]$, and endocrine status (e.g., thyroid hormone [14]). REE decreases with age $[15,16]$. The age related decline in REE could be due not only to the loss of FFM and an alteration in its metabolically active components, but also to the reduction in physical activity. It is well known that the reduction of physical activity leads to a reduction in REE and a decrease in FFM.

Energy homeostasis, as it is determined by the balance between calorie intake and energy expenditure, is regulated by interconnected neuroendocrine and autonomic pathways emanating from and controlled by the central nervous system [17].

\section{The Hypothalamus}

Many studies point out that the hypothalamus controls muscle glucose metabolism and its insulin sensitivity; in fact electrical stimulation of the Ventromedial Hypothalamus (VMH) increases glucose uptake in certain peripheral tissues, including skeletal muscle, Brown Adipose Tissue (BAT), and heart of rats. The hypothalamus, which is a key system component for regulation of energy homeostasis, continuously monitors signals that reflect energy status and initiates appropriate behavioural and metabolic responses [18]. It thus controls glucose utilization in insulin-sensitive organs, such as skeletal muscle, as well as whole-body energy metabolism [19-22]. Skeletal muscle is the principal site for glucose and fatty acid 
metabolism and it is responsible for insulin resistance associated with obesity and type 2 diabetes mellitus [23].

\section{BAT}

Mammals possess a specialized tissue termed BAT that expends calories to counteract hypothermia. The capacity to intensify energy expenditure by manipulating BAT activity is interesting from a therapeutic point of view, considering the discovery of metabolically active BAT in adult humans $[24,25]$.

It is hoped that stimulating the calorie burning capacity of BAT in humans will help contravene obesity and insulin resistance. Therefore a large number of resources have recently been mobilized in order to point out safe ways to exploit BAT thermogenesis, resulting in discovery of pathways that can potentially be targeted for therapeutic gain $[11,12,26-33]$. Our laboratory analyses have led to the discovery of an orexin-BAT axis.

\section{Orexins}

Orexins A and B are hypothalamic neuropeptides, involved in the regulation of feeding behavior, sleep-wakefulness rhythm, and neuroendocrine homeostasis [33-35].

These peptides derive from the prepro-orexin (preprohypocretin) gene, which encodes a precursor (130 amino acids in rodents, 131 residues in humans) that is cleaved into orexin A (synonymous with hypocretin-1; 33 amino acids) and orexin B (hypocretin-2; 28 residues) as reported in the figure 1 [36].

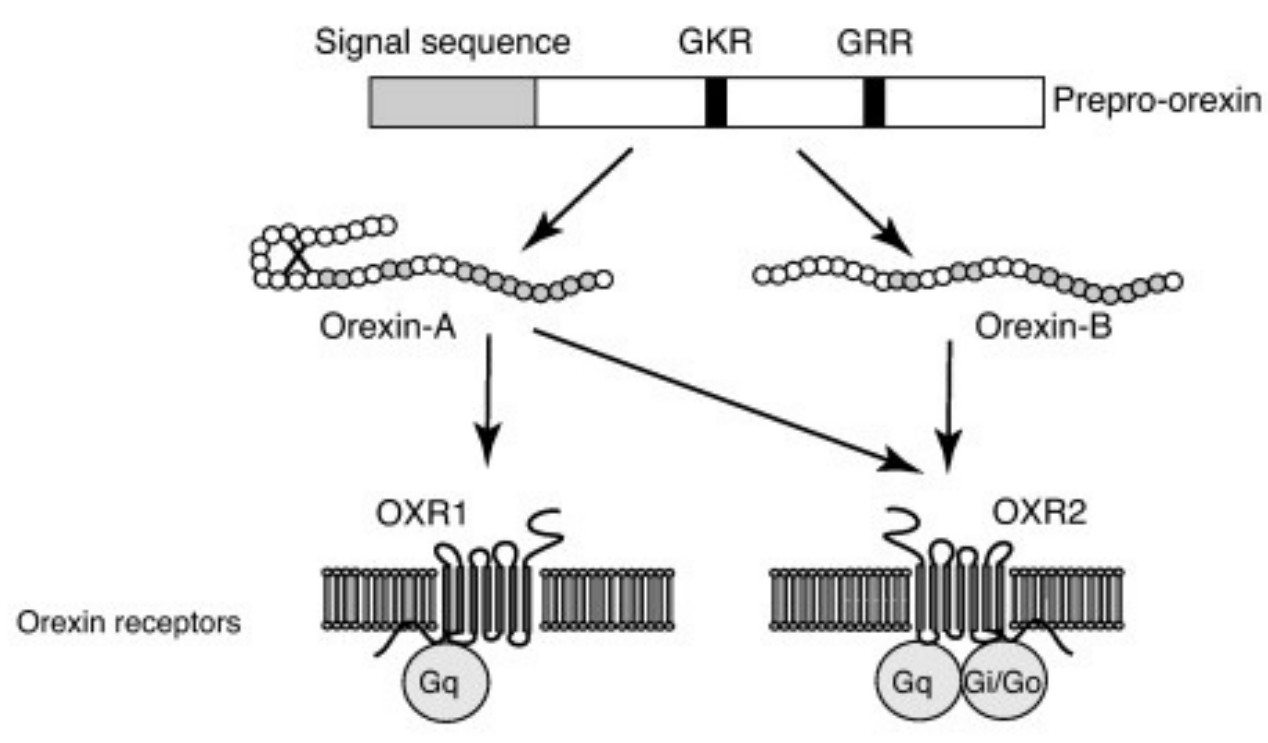

Figure 1: Orexin A and orexin B are derived from a common precursor peptide, prepro-orexin. The actions of orexins are carried out thanks to two receptors that have G protein denominated OXR-1 and OXR-2 receptors. OXR-1 is selective for orexin A, while OXR-2 shows similar affinity for both orexin A and orexin B. OXR-1 is coupled to the Gq subclass of heterotrimeric G proteins, while OXR-2 couples to Gi/o and /or GQ cell lines.

Orexins promote both waking and feeding [37]. A part from this central role, orexins have probabily peripheral effect and this was suggested by the detection of substantial levels of orexins in plasma [38], as well as the demonstration of orexin receptors in several peripheral tissues, including the Gastrointestinal Tract (GIT), endocrine pancreas, adrenal glands, and adipose tissue [39,40].

Snow et al. [41] have demonstrated that plasma orexin levels are one-fifth to one-eighth of orexin Cerebrospinal Fluid (CSF) values. However, the source of orexin in peripheral tissue is still unclear. Is orexin directly released into the blood stream or leaked from the cerebrospinal fluid? One possibility is that orexin is released from the pituitary since orexin-immunoreactive fibers are present in the median eminence and pituitary. The other possibility is that orexin is produced directly in peripheral tissues. Orexin-immunoreactive cells are observed in the gastrointestinal tract and pancreas. However, the question of orexin synthesis in peripheral tissue is still under discussion. Further studies are needed to better understand orexin physiology in peripheral tissues. Taken together, orexin neurons play an important role in coordinating central and peripheral states according to environmental changes, which is highly beneficial to survival in nature [42].

It has been proved that orexin-A influences several physiological variables. An Intracerebroventricular (ICV) injection of orexin-A induces an increase in heart rate, blood pressure, and metabolic rate, thus, indicating that this neuropeptide plays a role in the control of vegetative functions $[43,44]$.

These peptides cooperate with two G-protein-coupled receptors, orexin receptor-1 (hypocretin receptor-1) and orexin receptor-2 (hypocretin receptor-2). The orexin receptor- 1 selectively binds orexin A 100 times more avidly than orexin B, which is bound preferentially to the orexin receptor- 2 .

The expression pattern of mRNA encoding two orexin receptors (OX1R andOX2R) in the rat's brain has been demonstrated by Trivedi et al. [45]. Within the hypothalamus, expression for the OX1R mRNA was largely restricted in the Ventromedial $(\mathrm{VMH})$ and dorsomedial 
hypothalamic nuclei, while paraventricular nucleus, VMH, and arcuate nucleus contain high levels of OX2R mRNA, as well as in mammillary nuclei [46].

$\mathrm{Lu}$ et al. [47] have demonstrated that levels of OX1R mRNA significantly increased in the VMH of rats after $20 \mathrm{~h}$ of fasting. An initial decrease $(14 \mathrm{~h})$ and a subsequent increase $(20 \mathrm{~h})$ in OX1R mRNA levels after fasting were observed in the dorsomedial hypothalamic nucleus.

Levels of OX2R mRNA increased in the arcuate nucleus, but they didn't change in the dorsomedial hypothalamic nucleus and paraventricular hypothalamic nucleus following fasting. The timedependent and region-specific regulatory patterns of OX1R and OX2R suggest that they may participate in distinct neural circuits under the condition of food deprivation.

These evidences indicate that the two types of orexin receptors are involved in different responses. In addition, the presence of orexin receptors in other cerebral areas suggests that orexin-A plays additional functions [34].

It has been demonstrated that the orexins play a role in sleep regulation [48]. Deficiency in orexin neurotransmission results in the sleep disorder narcolepsy in mice, dogs, and humans [49]. Orexin-A also influences body temperature. In fact, an ICV administration of orexin-A induces an increase in firing rate of the sympathetic nerves to IBAT, accompanied with a rise in IBAT and colonic temperatures [50]. The simultaneous increase in heart rate and body temperature after an ICV injection of orexin-A shows a generalized activation of the sympathetic nervous system. Few studies have been made on the topic of the roles played by different cerebral areas involved in the induction of the abovementioned tachycardia and hyperthermia [51-53].

Orexin-A may partially mediate pressor response by increasing basal sympathetic activity, causing catecholamine release, modulating the vasopressin system [54], and stimulating renal and adrenal orexin receptors [55]. These considerations are further confirmed by Shirasaka et al.'s study, that has shown that experimental use orexin-A increase heart rate, renal sympathetic activity, catecholamine release, and mean arterial blood pressure [43].

Orexin derangements in patients with narcolepsy were associated with an increased body mass index and a higher risk of type-II diabetes mellitus [56,57]. Further, the discovery of a relationship between BAT and orexins levels also suggests new research on the possible roles of orexins in many anomalies involving REE.

The influence of orexin-A on sympathetic nervous system activity, blood pressure regulation, metabolic status and plasma glucose level may contribute to increase diabetics morbidity and mortality, as reported in the figure $2[4,11]$. It has been proved that orexins affect the plasma lipoprotein profile and insulin glucose homeostasis. Orexins stimulate insulin release from pancreatic cells in vivo and in vitro $[58,59]$.

Orexin neurons may also functionally interact with glucosesensitive neurons in the hypothalamus, notably the glucose-responsive cells (glucose-excited neurons: stimulated by rising glucose levels) found predominantly in the Ventromedial Nucleus (VMH), and the glucose-sensitive neurons (glucose-inhibited neurons: stimulated when glucose falls) that constitute $30 \%$ of Lateral Hypothalamic Area (LHA) neurons.
There are synaptic contacts between orexin neurons and glucosesensitive cells in the LHA, while orexin A specifically stimulates the glucose-sensitive cells [60]. On the contrary, orexin A inhibits glucoseresponsive neurons in the $\mathrm{VMH}$ [61]. Recent work suggests that some glucose-sensitive neurons express orexins [62]. In the medulla, orexin neurons innervate the Nucleus of The Solitary Tract (NTS), which is an important relay station that receives sensory signals, such as portal vein glucose availability and gastric distension from the viscera. These signals are conveyed to the hypothalamus [63].

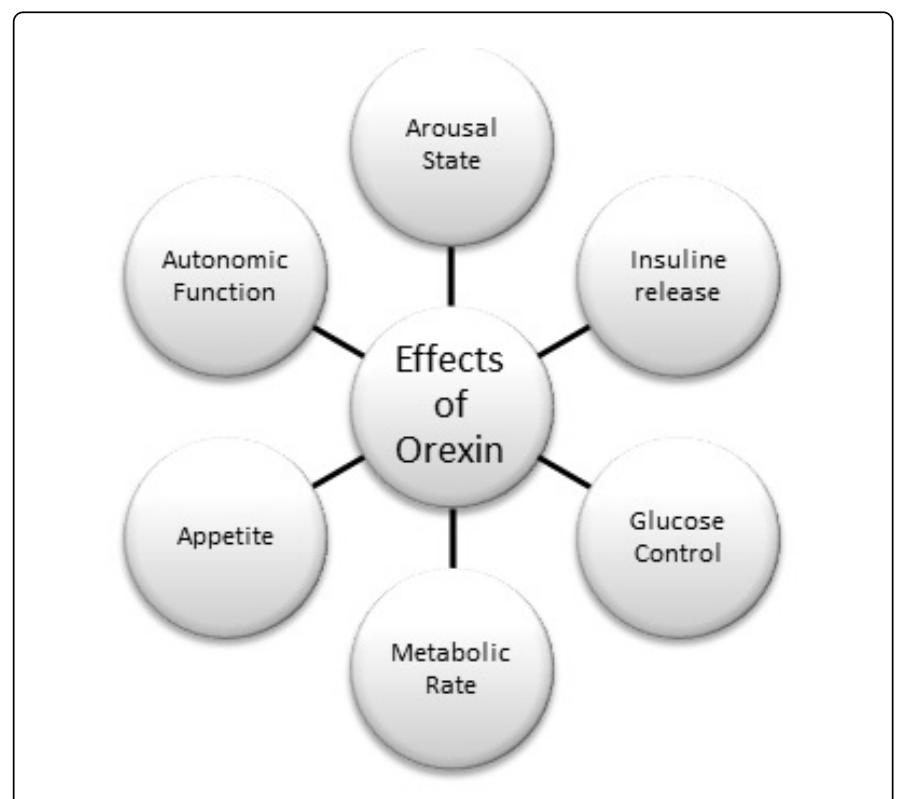

Figure 2: Effects of orexin in peripheral tissue and central nervous system

Sugar-sensing neurons exist in restricted brain regions, such as hypothalamus and brain stem, and they are classified into two groups, called Glucose-Excited (GE) neurons and Glucose-Inhibited (GI) neurons, in terms of the mode of response to extracellular glucose changes within physiological Cerebrospinal Fluid (CSF) range [64,65].

For instance, orexin neurons in the LHA and Neuropeptide Y (NPY)/Agouti-Related Peptide (AgRP) neurons in the ARC are glucose-inhibited, whereas Melanin-Concentrating Hormone $(\mathrm{MCH})$ neurons in LHA and Proopiomelanocortin (POMC) neurons in the ARC are glucose-excited [64,66].

The sugar sensing of orexin neurons, which is a major class of GI neurons, is metabolism-independent, since the glucose response is unaffected by glucokinase inhibitors, and mimicked by a nonmetabolizable glucose analog 2-deoxyglucose, although the accurate mechanisms, particularly the functional molecules relevant to glucoseinduced inhibition, have not yet been explained [67]. Orexin neurons are not inhibited by L-glucose, galactose, $\alpha$-methyl-D-glucoside, or fructose, whereas GE neurons can sense galactose [67]. More recently, it has been suggested that orexin neurons function as a "conditional glucosensor," because the electrical activity of orexin neurons is more potently inhibited by glucose when intracellular energy levels (i.e., cytosolic levels of pyruvate, lactate, or ATP) are low, whereas high energy levels attenuate the glucose response in orexin neurons [68]. 
A growing body of evidence suggest that orexin neuronal system has a decisive role in the modulation of glucose homeostasis $[69,70]$. However, the actions of orexin are not necessarily simple and this is due to the fact that orexin appears to bring to bear opposing effects probably depending on the experimental conditions. One type of action is the blood glucose-elevating effect, and the other is the blood glucose-lowering effect.

In fact, a bolus subcutaneous injection of orexin A (1 nmol) resulted in an increase in blood glucose and insulin levels in rats under non-fasting condition [71]. Similarly, infusion of orexin A (15 nmol) into the third cerebro-ventricle increased blood glucose and insulin levels, body temperature, and ambulation, without affecting uncoupling protein 1 expression in BAT under non-fasting and unanesthetized condition [72].

Besides, Yi et al. [73] have recently reported that a continuous ICV infusion of orexin A $(1 \mathrm{mmol} / \mathrm{L}, 5 \mu \mathrm{L} / \mathrm{h})$ into rats fasted for $5 \mathrm{~h}$ brought about an increase in plasma glucose levels, and prevented a daytime decrease of Endogenous Hepatic Glucose Production (EGP). Hepatic sympathetic, but not parasympathetic, denervation blocked the orexin induced apparent enhancement of EGP.

In addition, when the $\gamma$-aminobutyric acid receptor antagonist bicuculline was administered in the perifornical area in order to activate orexin neurons, basal EGP was increased, and insulinmediated suppression of EGP was attenuated, but the insulin-induced glucose disposal was enhanced.

These results demonstrate that central action of orexin stimulates sympathetic outflow to the periphery, leading to the promotion of EGP in the liver and glucose uptake in the skeletal muscle [73]. These actions of orexin seem to be reasonable in terms of survival in starvation, because when metabolic fuel levels are low, hypothalamic orexin neurons can be activated to supply the energy to muscle via hepatic glucose production, and support searching for food.

Several studies have focused on finding out the relationship between circulating orexin and fat mass and have proved that there is a strong correlation between low plasma orexin and obesity [39,74]. A significant issue is whether this naturally occurring biological peptide "orexin" in useful in weight management or obesity treatment. Observations made by Warwick PM [75] suggest that when orexin is peripherally injected, it activates thermogenesis, without limiting feeding or increasing physical activity. These encouraging observations have paved the way for clinical testing of the thermogenic potential of orexin [76].

Studies indicate a lower mortality in overweight and obese patients, while underweight patients appear to suffer from increased mortality. These observations show that adipose tissue can play an important metabolic role during insulin resistance.

The functions of key organs involved in peripheral glucose metabolism are dually regulated by the sympathetic and parasympathetic nervous systems [77]. Stimulation of the LHA increases the activity of hepatic vagal nerve, whereas stimulation of the VMH produces a strong inhibition of vagal nerve activity in anesthetized rats [78]. An anatomical analysis using retrograde neural tracer showed that orexin neurons in the LHA project to liver and adipose tissue [79].

Emerging evidence points out that orexin not only senses peripheral metabolic signals, but also controls glucose production and utilization in the peripheral tissues via the autonomic nervous system [70]. These conclusions demonstrate that orexin can function as a master regulator to coordinate the central and peripheral hormonal actions for the maintenance of glucose homeostasis.

Orexin fibers impinge upon sympathetic preganglionic neurons in the Intermediolateral column of the spinal cord (IML) that project to the liver and promote the glucose production [80-82]. Besides, orexin fibers are distributed throughout the rat brainstem including Dorsal Motor Nucleus of Vagus (DMNV) neurons and Nucleus Of The Solitary Tract (NTS) $[83,84]$. Orexin A and B directly depolarize the DMNV neurons, which is the major source of parasympathetic innervation to the peripheral tissues including liver [85]. It is therefore anticipated that glucose metabolism is dually regulated by orexin system through the changes in sympathetic and parasympathetic balance.

Low dose of orexin A (10 ng ICV) actually lowers lipolysis by suppressing sympathetic nerve activity (probably through parasympathetic innervation, [86]), whereas high-dose of orexin A (1000 ng ICV) promotes lipolysis through facilitation of the sympathetic nervous system [87].

In addition, low-dose of orexin A (10 ng i.v., $0.01 \mathrm{ng} \mathrm{ICV,} \mathrm{or} 5$ pmol into NTS) has a cardiovascular suppressive effect, whereas high-dose of orexin A (1000 ng i.v., $10 \mathrm{ng}$ ICV, or $>20$ pmol into NTS) conversely induces the cardiovascular excitatory effects $[88,89]$.

It has been reported that the circadian clock regulates active glucose and lipid metabolism in the liver and other peripheral tissues [90,91]. Orexin neurons receive dense inputs from the Suprachiasmatic Nucleus (SCN), the master circadian clock [81].

ICV injection of orexin antagonist completely prevented the endogenous rise in glucose levels at the end of the sleep period, indicating that orexin is an important factor to control the daily rhythm in plasma glucose concentrations [82]. Thus, orexin appears to play a pivotal role in the interconnection among biological clock, sleep/wake cycle, and glucose homeostasis. Although orexin A independently produces blood glucose-elevating and -lowering effects under different experimental conditions, the respective effects may be implicated in the rise and fall of blood glucose levels with circadian rhythm. Further studies need to be done in order to clarify the mechanisms with whom these opposing effects of orexin are adequately coordinated under physiological conditions.

The mechanisms through which orexins regulate glucose metabolism through OXR-1 and OXR-2 binding have not been extensively examined. Existing evidence suggests that orexins induce glucose production in the liver and help glucose uptake in skeletal muscle [73,92]. In addition it has been shown that orexins A and B differentially regulate glucagon release from pancreas [93].

In conclusion, orexin should be regarded as an important peptide in the modulation of homeostasis of glucose and pharmacological tools should be examined to regulate the orexinergic system in the pathological conditions.

\section{References}

1. Yach D, Stuckler D, Brownell KD (2006) Epidemiologic and economic consequences of the global epidemics of obesity and diabetes. Nat Med 12: 62-66.

2. Runge CF (2007) Economic consequences of the obese. Diabetes 56: 2668-2672. 
3. Must A, Spadano J, Coakley EH, Field AE, Colditz G, et al. (1999) The disease burden associated with overweight and obesity. JAMA 282: 1523-1529.

4. Calle EE, Rodriguez C, Walker-Thurmond K, Thun MJ (2003) Overweight, obesity, and mortality from cancer in a prospectively studied cohort of U.S. adults. N Engl J Med 348: 1625-1638.

5. Friedenberg FK, Xanthopoulos M, Foster GD, Richter JE (2008) The association between gastroesophageal reflux disease and obesity. Am J Gastroenterol 103: 2111-2122.

6. Field AE, Coakley EH, Must A, Spadano JL, Laird N, et al. (2001) Impact of overweight on the risk of developing common chronic diseases during a 10-year period. Arch Intern Med 161: 1581-1586.

7. van Vliet-Ostaptchouk JV, Nuotio ML, Slagter SN, Doiron D, Fischer K, et al. (2014) The prevalence of metabolic syndrome and metabolically healthy obesity in Europe: a collaborative analysis of ten large cohort studies. BMC Endocr Disord 14: 9.

8. Flegal KM, Carroll MD, Ogden CL, Johnson CL (2002) Prevalence and trends in obesity among US adults, 1999-2000. JAMA 288: 1723-1727.

9. United States Census Bureau. [Accessed 3 September 2009] U.S. and world population clocks. Updated in real time.

10. Wang Y, Beydoun MA (2007) The obesity epidemic in the United Statesgender, age, socioeconomic, racial/ethnic, and geographic characteristics: a systematic review and meta-regression analysis. Epidemiologic reviews 29: 6-28.

11. Weyer C, Snitker S, Rising R, Bogardus C, Ravussin E (1999) Determinants of energy expenditure and fuel utilization in man: effects of body composition, age, sex, ethnicity and glucose tolerance in 916 subjects. Int J Obes Relat Metab Disord 23: 715-722.

12. Messina G, Vicidomini C, Viggiano A, Tafuri D, Cozza V, et al. (2012) Enhanced parasympathetic activity of sportive women is paradoxically associated to enhanced resting energy expenditure. Autonomic Neuroscience 169:102-106.

13. Welle S, Schwartz RG, Statt M (1991) Reduced metabolic rate during beta-adrenergic blockade in humans. Metabolism 40: 619-622.

14. Danforth E Jr, Burger A (1984) The role of thyroid hormones in the control of energy expenditure. Clin Endocrinol Metab 13: 581-595.

15. Roubenoff R, Hughes VA, Dallal GE, Nelson ME, Morganti C, et al. (2000) The effect of gender and body composition method on the apparent decline in lean mass-adjusted resting metabolic rate with age. J Gerontol A Biol Sci Med Sci 55: M757-760.

16. Monda M, Messina G, Mangoni C, De Luca B (2008) Resting energy expenditure and fat-free mass do not decline during aging in severely obese women. Clin Nutr 27: 657-659.

17. Flier JS (2004) Obesity wars: molecular progress confronts an expanding epidemic. Cell 116: 337-350.

18. Sudo M, Minokoshi Y, Shimazu T (1991) Ventromedial hypothalamic stimulation enhances peripheral glucose uptake in anesthetized rats. Am J Physiol 261: E298-303.

19. Schwartz MW, Woods SC, Porte D Jr, Seeley RJ, Baskin DG (2000) Central nervous system control of food intake. Nature 404: 661-671.

20. Kamohara S, Burcelin R, Halaas JL, Friedman JM, Charron MJ (1997) Acute stimulation of glucose metabolism in mice by leptin treatment. Nature 389: 374-377.

21. Haque MS, Minokoshi Y, Hamai M, Iwai M, Horiuchi M, et al. (1999) Role of the sympathetic nervous system and insulin in enhancing glucose uptake in peripheral tissues after intrahypothalamic injection of leptin in rats. Diabetes 48: 1706-1712.

22. Minokoshi Y, Haque MS, Shimazu T (1999) Microinjection of leptin into the ventromedial hypothalamus increases glucose uptake in peripheral tissues in rats. Diabetes 48: 287-291.

23. Kahn BB, Flier JS (2000) Obesity and insulin resistance. J Clin Invest 106: 473-481.

24. Wade GN, Gray JM (1979) Gonadal effects on food intake and adiposity: a metabolic hypothesis. Physiol Behav 22: 583-593.
25. Monda M, Amaro S, De Luca B (1994) Non-shivering thermogenesis during prostaglandin E1 fever in rats: role of the cerebral cortex. Brain Res 651: 148-154.

26. Monda M, Pittman QJ (1993) Cortical spreading depression blocks prostaglandin E1 and endotoxin fever in rats. Am J Physiol 264: R456-459.

27. Dagnault A, Ouerghi D, Richard D (1993) Treatment with alpha-helicalCRF(9-41) prevents the anorectic effect of 17-beta-estradiol. Brain Res Bull 32: 689-692.

28. Poehlman ET, Goran MI, Gardner AW, Ades PA, Arciero PJ, et al. (1993) Determinants of decline in resting metabolic rate in aging females. Am J Physiol 264: E450-455.

29. Gardner AW, Poehlman ET (1994) Leisure time physical activity is a significant predictor of body density in men. J Clin Epidemiol 47: 283-291.

30. Monda M, Messina G, Vicidomini C, Viggiano A, Mangoni C, et al. (2006) Activity of autonomic nervous system is related to body weight in pre-menopausal, but not in post-menopausal women. Nutr Neurosci 9: 141-145.

31. De Luca B, Monda M, Amaro S, Pellicano MP, Cioffi LA (1989) Lack of diet-induced thermogenesis following lesions of paraventricular nucleus in rats. Physiol Behav 46: 685-691.

32. De Luca B, Monda M, Amaro S, Pellicano MP (1989) Thermogenetic changes following frontal neocortex stimulation. Brain Res Bull 22: 1003-1007.

33. Monda M, Viggiano AN, Viggiano A, Viggiano E, Lanza A, et al. (2005) Hyperthermic reactions induced by orexin A: role of the ventromedial hypothalamus. Eur J Neurosci 22: 1169-1175.

34. Kukkonen JP, Holmqvist T, Ammoun S, Akerman KE (2002) Functions of the orexinergic/hypocretinergic system. Am J Physiol Cell Physiol 283: C1567-1591.

35. Viggiano A, Viggiano A, Monda M, Turco I, Incarnato L, et al. (2006) Annurca apple-rich diet restores long-term potentiation and induces behavioral modifications in aged rats. Exp Neurol 199: 354-361.

36. Sakurai T, Amemiya A, Ishii M, Matsuzaki I, Chemelli RM, et al. (1998) Orexins and orexin receptors-a family of hypothalamic neuropeptides and $G$ protein-coupled receptors that regulate feeding behavior. Cell 92:573-585.

37. Sweet DC, Levine AS, Billington CJ, Kotz CM (1999) Feeding response to central orexins. Brain Res 821: 535-538.

38. Adam JA, Menheere PP, van Dielen FM, Soeters PB, Buurman WA, et al. (2002) Decreased plasma orexin-A levels in obese individuals. Int J Obes Relat Metab Disord 26: 274-276.

39. Heinonen MV, Purhonen AK, Mäkelä KA, Herzig KH (2008) Functions of orexins in peripheral tissues. Acta Physiol (Oxf) 192: 471-485.

40. Digby JE, Chen J, Tang JY, Lehnert H, Matthews RN, et al. (2006) Orexin receptor expression in human adipose tissue: effects of orexin-A and orexin-B. J Endocrinol 191: 129-136.

41. Snow A, Gozal E, Malhotra A, Tiosano D, Perlman R, et al. (2002) Severe hypersomnolence after pituitary/hypothalamic surgery in adolescents: clinical characteristics and potential mechanisms. Pediatrics 110:174.

42. Tsunematsu T, Yamanaka A (2012) The role of orexin/hypocretin in the central nervous system and peripheral tissues. Vitam Horm 89: 19-33.

43. Shirasaka T, Nakazato M, Matsukura S, Takasaki M, Kannan H (1999) Sympathetic and cardiovascular actions of orexins in conscious rats. Am J Physiol 277: R1780-1785.

44. Lubkin M, Stricker-Krongrad A (1998) Independent feeding and metabolic actions of orexins in mice. Biochem Biophys Res Commun 253: 241-245.

45. Trivedi P, Yu H, MacNeil DJ, Van der Ploeg LH, Guan XM (1998) Distribution of orexin receptor mRNA in the rat brain. FEBS Lett 438: 71-75.

46. Zhang S, Blache D, Vercoe PE, Adam CL, Blackberry MA, et al. (2005) Expression of orexin receptors in the brain and peripheral tissues of the male sheep. Regul Pept 124: 81-87. 
47. Lu XY, Bagnol D, Burke S, Akil H, Watson SJ (2000) Differential distribution and regulation of OX1 and OX2 orexin/hypocretin receptor messenger RNA in the brain upon fasting. Horm Behav 37: 335-344.

48. Beuckmann CT, Yanagisawa M (2002) Orexins: from neuropeptides to energy homeostasis and sleep/wake regulation. J Mol Med (Berl) 80: 329-342.

49. Monda M, Viggiano A, Viggiano A, Fuccio F, De Luca V (2004) Injection of orexin A into the diagonal band of Broca induces sympathetic and hyperthermic reactions. Brain Res 1018: 265-271.

50. Monda M, Viggiano A, Mondola P, De Luca V (2001) Inhibition of prostaglandin synthesis reduces hyperthermic reactions induced by hypocretin-1/orexin A. Brain Res 909: 68-74.

51. Monda M, Sullo A, De Luca E, Pellicano MP (1996) Lysine acetylsalicylate modifies aphagia and thermogenic changes Induced by lateral hypothalamic lesion. American Journal of Physiology 271:1638-1642.

52. Monda M, Amaro S, Sullo A, De Luca B (1994) Posterior hypothalamic activity and cortical control during the PGE1 hyperthermia. Neuroreport 6: 135-139.

53. Monda M, Amaro S, Sullo A, De Luca B (1995) Injection of muscimol in the posterior hypothalamus reduces the PGE1-hyperthermia in the rat. Brain Res Bull 37: 575-580.

54. Al-Barazanji KA, Wilson S, Baker J, Jessop DS, and Harbuz M (2001) Central orexin-A activates hypothalamic-pituitaryadrenal axis and stimulates hypothalamic corticotropin releasing factor and arginine vasopressin neurones in conscious rats. Journal of Neuroendocrinology 13: $421-424$.

55. Jöhren O, Neidert SJ, Kummer M, Dendorfer A, Dominiak P (2001) Prepro-orexin and orexin receptor mRNAs are differentially expressed in peripheral tissues of male and female rats. Endocrinology 142: 3324-3331.

56. Schuld A, Hebebrand J, Geller F, Pollmächer T (2000) Increased bodymass index in patients with narcolepsy. Lancet 355: 1274-1275.

57. Honda Y, Doi Y, Ninomiya R, Ninomiya C (1986) Increased frequency of non-insulin-dependent diabetes mellitus among narcoleptic patients. Sleep 9: 254-259.

58. Taylor MM, Samson WK (2003) The other side of the orexins: endocrine and metabolic actions. Am J Physiol Endocrinol Metab 284: E13-17.

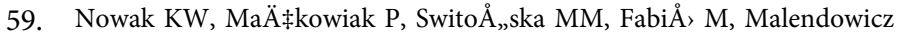
LK (2000) Acute orexin effects on insulin secretion in the rat: in vivo and in vitro studies. Life Sci 66: 449-454.

60. Liu XH, Morris R, Spiller D, White M, Williams G (2001) Orexin a preferentially excites glucose-sensitive neurons in the lateral hypothalamus of the rat in vitro. Diabetes 50: 2431-2437.

61. Shiraishi T, Oomura Y, Sasaki K, Wayner MJ (2000) Effects of leptin and orexin-A on food intake and feeding related hypothalamic neurons. Physiol Behav 71: 251-261.

62. Muroya S, Uramura K, Sakurai T, Takigawa M, Yada T (2001) Lowering glucose concentrations increases cytosolic $\mathrm{Ca} 2+$ in orexin neurons of the rat lateral hypothalamus. Neurosci Lett 309: 165-168.

63. Ter Horst GJ, de Boer P, Luiten PG, van Willigen JD (1989) Ascending projections from the solitary tract nucleus to the hypothalamus. A Phaseolus vulgaris lectin tracing study in the rat. Neuroscience 31: 785-797.

64. Burdakov D, González JA (2009) Physiological functions of glucoseinhibited neurones. Acta Physiol (Oxf) 195: 71-78.

65. Gonzàlez JA, Reimann F, Burdakov D (2009) Dissociation between sensing and metabolism of glucose in sugar sensing neurones. J Physiol 587: 41-48.

66. Burdakov D, Luckman SM, Verkhratsky A (2005) Glucose-sensing neurons of the hypothalamus. Philos Trans R Soc Lond B Biol Sci 360: 2227-2235.

67. González JA, Jensen LT, Fugger L, Burdakov D (2008) Metabolismindependent sugar sensing in central orexin neurons. Diabetes 57: 2569-2576.
68. Karnani M, Burdakov D (2011) Multiple hypothalamic circuits sense and regulate glucose levels. Am J Physiol Regul Integr Comp Physiol 300: R47-55.

69. Venner A, Karnani MM, Gonzalez JA, Jensen LT, Fugger L, et al. (2011) Orexin neurons as conditional glucosensors: paradoxical regulation of sugar sensing by intracellular fuels. J Physiol 589: 5701-5708.

70. Tsuneki H, Wada T, Sasaoka T (2010) Role of orexin in the regulation of glucose homeostasis. Acta Physiol (Oxf) 198: 335-348.

71. Viggiano A, Vicidomini C, Monda M, Carleo D, Carleo R, et al. (2009) Fast and low-cost analysis of heart rate variability reveals vegetative alterations in noncomplicated diabetic patients. J Diabetes Complications 23: 119-123.

72. Yoshimichi G, Yoshimatsu H, Masaki T, Sakata T (2001) Orexin-A regulates body temperature in coordination with arousal status. Exp Biol Med (Maywood) 226: 468-476.

73. Yi CX, Serlie MJ, Ackermans MT, Foppen E, Buijs RM, et al. (2009) A major role for perifornical orexin neurons in the control of glucose metabolism in rats. Diabetes 58: 1998-2005.

74. Messina G, De Luca V, Viggiano A, Ascione A, Iannaccone T, et al. (2013) Autonomic nervous system in the control of energy balance and body weight: personal contributions. Neurol Res Int 2013: 639280.

75. Warwick PM, Busby R (1990) Influence of mild cold on $24 \mathrm{~h}$ energy expenditure in 'normally' clothed adults. Br J Nutr 63: 481-488.

76. Messina G, Viggiano A, De Luca V, Messina A, Chieffi S, et al. (2013) Hormonal changes in menopause and orexin-a action. Obstet Gynecol Int 2013: 209812.

77. Marino JS, Xu Y, Hill JW (2011) Central insulin and leptin-mediated autonomic control of glucose homeostasis. Trends Endocrinol Metab 22: 275-285.

78. Yoshimatsu H, Niijima A, Oomura Y, Katafuchi T (1988) Lateral and ventromedial hypothalamic influences on hepatic autonomic nerve activity in the rat. Brain Res Bull 21: 239-244.

79. Stanley S, Pinto S, Segal J, Pérez CA, Viale A, et al. (2010) Identification of neuronal subpopulations that project from hypothalamus to both liver and adipose tissue polysynaptically. Proceedings of the National Academy of Sciences of the United States of America 107: 7024-7029.

80. van den Top M, Nolan MF, Lee K, Richardson PJ, Buijs RM, et al. (2003) Orexins induce increased excitability and synchronisation of rat sympathetic preganglionic neurones. J Physiol 549: 809-821.

81. Kalsbeek A, Yi CX, La Fleur SE, Fliers E (2010) The hypothalamic clock and its control of glucose homeostasis. Trends Endocrinol Metab 21: 402-410.

82. Kalsbeek A, Scheer FA, Perreau-Lenz S, La Fleur SE, Yi CX, et al. (2011) Circadian disruption and SCN control of energy metabolism. FEBS Lett 585: 1412-1426.

83. Peyron C, Tighe DK, van den Pol AN, de Lecea L, Heller HC, et al. (1998) Neurons containing hypocretin (orexin) project to multiple neuronal systems. J Neurosci 18: 9996-10015.

84. Harrison TA, Chen CT, Dun NJ, Chang JK (1999) Hypothalamic orexin A-immunoreactive neurons project to the rat dorsal medulla. Neurosci Lett 273: 17-20.

85. Hwang LL, Chen CT, Dun NJ (2001) Mechanisms of orexin-induced depolarizations in rat dorsal motor nucleus of vagus neurones in vitro. J Physiol 537: 511-520.

86. Kreier F, Buijs RM (2007) Evidence for parasympathetic innervation of white adipose tissue, clearing up some vagaries. American journal of physiology. Regulatory, integrative and comparative physiology 293:R548- R549.

87. Shen J, Tanida M, Yao JF, Niijima A, Nagai K (2008) Biphasic effects of orexin-A on autonomic nerve activity and lipolysis. Neurosci Lett 444: 166-171.

88. Tanida M, Niijima A, Shen J, Yamada S, Sawai H, et al. (2006) Dosedifferent effects of orexin-A on the renal sympathetic nerve and blood pressure in urethane-anesthetized rats. Experimental biology and 
Citation: Messina G, Dalia C, Tafuri D, Palmieri F, Dato A, et al. (2014) Orexin A Controls Glucose Metabolism . J Diabetes Metab 5: 398. doi: 10.4172/2155-6156.1000398

Page 7 of 7

medicine / Society for Experimental Biology and Medicine 231: 1616-1625.

89. Shih CD, Chuang YC (2007) Nitric oxide and GABA mediate bidirectional cardiovascular effects of orexin in the nucleus tractus solitarii of rats. Neuroscience 149: 625-635.

90. Bass J, Takahashi JS (2010) Circadian integration of metabolism and energetics. Science 330: 1349-1354.

91. Froy O (2010) Metabolism and circadian rhythms--implications for obesity. Endocr Rev 31: 1-24.
92. Shiuchi T, Haque MS, Okamoto S, Inoue T, Kageyama H, et al. (2009) Hypothalamic orexin stimulates feeding-associated glucose utilization in skeletal muscle via sympathetic nervous system. Cell Metab 10: 466-480.

93. Adeghate E, Hameed R (2011) Mechanism of orexin B-stimulated insulin and glucagon release from the pancreas of normal and diabetic rats. Pancreas 40: 131-136. 